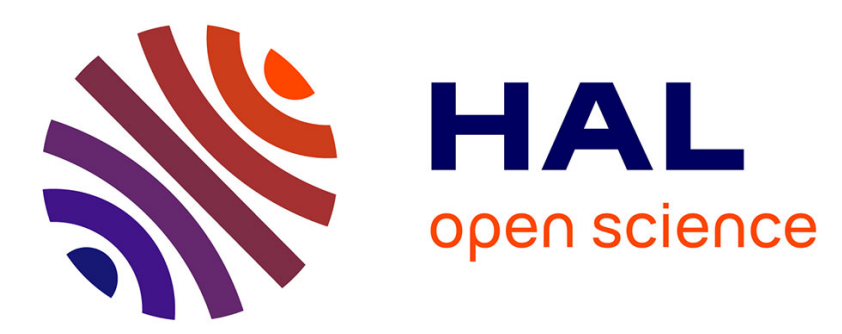

\title{
Multinomial logit estimation of a diameter growth matrix model of two Mediterranean pine species in Spain
}

Escalante, Pando, Ordoñez, Bravo

\section{To cite this version:}

Escalante, Pando, Ordoñez, Bravo. Multinomial logit estimation of a diameter growth matrix model of two Mediterranean pine species in Spain. Annals of Forest Science, 2011, 68 (4), pp.715-726. 10.1007/s13595-011-0088-9 . hal-00930821

\section{HAL Id: hal-00930821 \\ https://hal.science/hal-00930821}

Submitted on 1 Jan 2011

HAL is a multi-disciplinary open access archive for the deposit and dissemination of scientific research documents, whether they are published or not. The documents may come from teaching and research institutions in France or abroad, or from public or private research centers.
L'archive ouverte pluridisciplinaire HAL, est destinée au dépôt et à la diffusion de documents scientifiques de niveau recherche, publiés ou non, émanant des établissements d'enseignement et de recherche français ou étrangers, des laboratoires publics ou privés. 


\title{
Multinomial logit estimation of a diameter growth matrix model of two Mediterranean pine species in Spain
}

\author{
Ernesto Escalante • Valentín Pando • \\ Cristóbal Ordoñez $\cdot$ Felipe Bravo
}

Received: 18 August 2010 / Accepted: 6 December 2010 /Published online: 10 June 2011

(C) INRA and Springer Science+Business Media B.V. 2011

\begin{abstract}
- Introduction Understanding diameter growth of the Mediterranean pine species is fundamental for evaluating and making appropriate strategic decisions in forest management. A matrix diameter growth model for two Mediterranean pine forest ecosystems in Spain has been developed.

- Methods Multinomial logistic (MNL) regression was employed to estimate the transition probabilities of a matrix growth model. The model combines individual tree and stand attributes and explores the effects of independent variables and their relationships with tree size and the probabilities of stand diameter growth. The aim was to predict growth of individual trees by diameter class for a 5-year period.

- Results MNL model results for diameter growth gave better predictions for Maritime pine (Pinus pinaster Aiton) than for Scots pine (Pinus sylvestris L.). Stand simulations showed that diameter growth probabilities depended on productivity and stand density. Stand simulations under
\end{abstract}

Handling Editor: Matthias Dobbertin

E. Escalante $\cdot$ V. Pando $\cdot$ C. Ordoñez $\cdot$ F. Bravo

Sustainable Forest Management Research Institute,

Universidad de Valladolid-INIA,

Av. De Madrid,

s/n 34004 Palencia, Spain

E. Escalante $(\varangle) \cdot$ C. Ordoñez $\cdot$ F. Bravo

Departamento de Producción Vegetal y Recursos Forestales,

Universidad de Valladolid,

Av. De Madrid,

s/n 34004 Palencia, Spain

e-mail: escalante@gmail.com

V. Pando

Departamento de Estadística e Investigación Operativa,

Universidad de Valladolid,

Av. De Madrid,

s/n 34004 Palencia, Spain fixed conditions showed that the probabilities of diameter growth increased as site productivity increased and decreased with increased stand density index.

- Conclusions This study demonstrates the usefulness of matrix growth models as tools to predict growth in Mediterranean pine forests. Stand density and site productivity are key factors in explaining Scots pine and Maritime pine forest growth in the study area.

Keywords Diameter class · Growth · Multinomial logit . Stand simulations $\cdot$ Transition probabilities

\section{Introduction}

Matrix population models are key tools in demographic studies based on the analysis of survival, growth, and reproduction data. In operational forestry, assessing the long-term sustainability of forest practices and adequately estimating and projecting forest growth under different climate and management scenarios could allow foresters to make appropriate decisions with significant consequences at both economic and ecological levels. Matrix models have been applied in forestry (Usher 1966, 1969; Buongiorno and Michie 1980; Buongiorno et al. 1995) because they are conceptually simple (Buongiorno and Michie 1980) and useful for predicting the dynamics of the number of trees within individual diameter classes as a function of time. Such critical information is needed to simulate stands affected by different harvest scenarios (Volin and Buongiorno 1996).

Matrix models have been widely used with temperate and tropical forests. López et al. (2008) showed a method for estimating the long-term sustainable harvest rates and the stable diameter distributions of uneven-aged managed 
Beech (Fagus sylvatica L.) stands in northwestern Navarra (Spain) using a projection matrix model. This methodology has also been applied in tropical and subtropical forests (Osho 1991; Spathelf and Durlo 2001) and in temperate forests (Roberts and Hruska 1986; Monserud and Sterba 1999; Hao et al. 2005), but not in Mediterranean forests. Matrix models normally require grouping trees into size classes that are usually based on diameter at breast height (Picard et al. 2003; Shimatani et al. 2007). Diameter increment (Lowell and Mitchell 1987) is a useful proxy for tree biomass growth and can be predicted by probabilistic models based on multinomial distribution.

Multinomial logit (MNL) models are frequently used in market decisions (Wang et al. 2007), recreational activities (Mogas et al. 2006), and computational systems (Prinzie and Van den Poel 2008). In forestry applications, they have been used in operational forestry (Kurttila et al. 2001), for valuing ancient forest ecosystems (Englin et al. 2006), in tropical dry forests (Boltz and Carter 2006), and to determine tree quality in natural uneven-aged pine stands (Prestemon and Buongiorno 2000). However, this approach has not been used before to model tree diameter growth in Mediterranean forests.

In this paper, we attempt to develop a diameter growth model useful for decision making in two Mediterranean pine ecosystems using MNL estimation. Our goal was to develop a growth model using transition matrix elements based on probabilistic approach for diameter class which would adequately predict change in tree diameter growth. The MNL model enabled us to simulate stand development dynamics, with transitions influenced by changing characteristics.

\section{Materials and methods}

\subsection{Study area and focus species}

The study was conducted in Scots pine (Pinus sylvestris L.) and Maritime pine (Pinus pinaster Ait.) stands in the Central and Iberian Mountain Range Systems in Spain $\left(0^{\circ} 37^{\prime}-4^{\circ} 12^{\prime} \mathrm{W}, 39^{\circ} 48^{\prime}-42^{\circ} 58^{\prime} \mathrm{N}\right)$. The altitude of Maritime pine stands ranges from 990 to 1,200 m.a.s.l. and for Scots pine stands from 1,270 to 2,210 m.a.s.l. Scots pine is one of the most important species in Europe, dominating forest landscapes together with other species in boreal areas and Mediterranean mountains. In Spain, Scots pine stands occupy 840,000 ha as monospecific stands and 370,000 ha as mixed-forest stands. Maritime pine is a conifer from the western Mediterranean Basin, covering more than 4 million hectares over wide ranges of elevation, climate, and soil. As the most extensive conifer in Spanish forests, it covers approximately 1,200,000 ha, including natural and artificial stands (Bravo-Oviedo et al.
2004); over 700,000 ha are pure stands and 600,000 ha are mixed-forest stands, most of them in the Mediterranean areas (Río et al. 2004). Silviculture in the area is based on natural regeneration, and silvicultural interventions are not frequent at the early stages of development.

\subsection{Data}

Data from 101 permanent sample plots of Scots pine stands and 90 plots of Maritime pine stands were recorded (7,316 trees tallied overall). These plots were installed between 2002 and 2004. The plots were located along the area of distribution of the species studied and represent the existing range of ages, stand densities, and sites. Plots consisted of three concentric subplots with radii of 5, 10, and $15 \mathrm{~m}$ each. For these subplots, the minimum diameter at breast height (DBH) was recorded at 7.5, 12.5, and $22.5 \mathrm{~cm}$, respectively. At plot establishment, the following data were recorded for every sample tree: species, DBH (trunk diameter outside bark at $1.3 \mathrm{~m}$ above the ground), total height (HT, meters), height to crown base (HCB, meters), height to the largest crown width (HLCW, meters), and horizontal distance from plot center to the vertical axis of the tree in meters $(D$, meters). Diameters were measured with a caliper in two perpendicular directions (to the nearest millimeter). Forest stands ranged in age from 20 to 188 . A summary of the characteristics of the plots used in the study is presented in Table 1.

It was necessary to backdate all of the tree measurements to estimate their values at the start of the previous 5-year growth. Tree attribute backdating was obtained using the methodology proposed by Hann and Hanus (2001). More information about the backdating process used can be found in Lizarralde (2008). No thinning treatments or harvesting operations were conducted in the sample plots in the previous 5-year period.

\subsection{Statistical analysis}

Diameter classes were defined at $1-\mathrm{cm}$ intervals and the growth interval defined as a 5-year period. Data were classified in $I$ diameter size classes. Fifty-nine diameter classes for Scots pine stands and 54 diameter classes for Maritime pine stands were used, respectively. MNL models were used to model relationships between a polytomous response variable and a set of regressor variables. A discrete random variable $Y$ was then defined as the number of size classes advanced by an individual tree during a period of time. The support of $Y$ was defined by the set $\{0,1, \ldots, K\}$, where $K$ was the maximum number of size classes advanced. After observing our dataset, we consider $K=5$ for Scots pine and $K=4$ for Maritime pine. Let $P k$ with $k=0,1, \ldots K$ represent the probability function for variable $Y$, i.e., $p_{k}=p(Y=k)$. Therefore, $P k$ is the probability for an individual tree to grow $k$ diameter classes 
Table 1 Summary statistics of the independent variables and description of the stands
$D B H$ diameter at breast height over bark (in centimeters), $Q M D$ quadratic mean diameter (in centimeters), $N$ number of trees (per hectare), $B A$ basal area (in square meters per tree), $B A L$ basal area larger trees (in square meters per hectares), SI site index (or productivity), $A$ stand age (in years), HSI Hart-

Becking spacing index, SDI

Reineke's stand density index, $D D B H$ distance from $\mathrm{DBH}$ of the individual tree to the upper limit of its size class (in centimeters)

\begin{tabular}{|c|c|c|c|c|c|}
\hline Variable & Mean & Minimum & Maximum & Standard deviation & Standard error \\
\hline \multicolumn{6}{|c|}{ Pinus sylvestris L. (4,071 trees in 101 plots) } \\
\hline $\mathrm{DBH}_{t}$ & 30.119 & 6.130 & 64.280 & 9.889 & 0.15498 \\
\hline $\mathrm{DBH}_{t+5}$ & 31.121 & 8.000 & 66.500 & 9.932 & 0.15567 \\
\hline SI & 24.101 & 12.580 & 38.020 & 5.174 & 0.08109 \\
\hline$A$ & 89.182 & 30.250 & 188.250 & 35.264 & 0.55269 \\
\hline $\mathrm{BA}$ & 1.229 & 0.000 & 4.590 & 0.622 & 0.00975 \\
\hline$N$ & 1027.868 & 212.210 & $4,594.270$ & 937.163 & 14.68807 \\
\hline SDI & 1021.708 & 362.260 & $1,546.710$ & 230.919 & 3.61917 \\
\hline HSI & 29.495 & 17.350 & 85.070 & 8.814 & 0.13814 \\
\hline BAL & 28.747 & 0.000 & 77.620 & 16.484 & 0.25834 \\
\hline QMD & 29.679 & 12.840 & 50.450 & 8.465 & 0.13266 \\
\hline$D_{\mathrm{DBH}}$ & 0.499 & 0.000 & 1.000 & 0.289 & 0.00453 \\
\hline \multicolumn{6}{|c|}{ Pinus pinaster Ait. (3,542 trees in 90 plots) } \\
\hline $\mathrm{DBH}_{t}$ & 25.724 & 5.980 & 59.100 & 7.831 & 0.13158 \\
\hline $\mathrm{DBH}_{t+5}$ & 26.750 & 7.650 & 60.050 & 7.768 & 0.13052 \\
\hline SI & 14.674 & 7.110 & 25.060 & 4.453 & 0.07482 \\
\hline$A$ & 71.146 & 20.750 & 127.500 & 29.287 & 0.49209 \\
\hline BA & 0.978 & 0.000 & 3.880 & 0.373 & 0.00627 \\
\hline $\mathrm{N}$ & $1,055.871$ & 159.150 & $4,594.270$ & 659.802 & 11.08637 \\
\hline SDI & 834.841 & 377.690 & $1,459.010$ & 170.063 & 2.85749 \\
\hline HSI & 44.039 & 18.880 & 95.120 & 10.657 & 0.17907 \\
\hline BAL & 21.344 & 0.000 & 57.080 & 12.690 & 0.21323 \\
\hline QMD & 24.760 & 10.280 & 43.510 & 6.682 & 0.11227 \\
\hline$D_{\mathrm{DBH}}$ & 0.503 & 0.001 & 1.000 & 0.286 & 0.00481 \\
\hline
\end{tabular}

in a time period, which we called $k$ upgrowth probability. With this notation, MNL regression to estimate the probabilities $P k$ was employed using individual tree and stand attributes as explanatory variables.

Based on the data available for this study, individual tree attributes such as DBH (DBH, centimeters); distance from $\mathrm{DBH}$ of the individual tree to the upper limit of its size class $\left(D_{\mathrm{DBH}}\right.$, centimeters); basal area (BA, square meters); basal area in larger trees (BAL, square meters per hectare); and stand variables such as number of trees $(N$, per hectare), Reineke stand density index (SDI), Hart-Becking index (HSI) or relative spacing index, stand age ( $A$, years), site index (SI), and quadratic mean diameter (QMD, square meters per hectare) were analyzed. These different candidate models were tested and a stepwise method was used to select the independent variables. Finally, seven explanatory variables were selected for use in MNL regression $(P>0.05)$. Goodness of fit for all models was examined (Nagelkerke 1991) and adjusted $R^{2}$ measures computed (McFadden 1979). The best models were selected using Akaike's information criterion (AIC).

Two different MNL models were estimated and selected for each dataset (by species). The first was a basic model that showed the importance of the choice of seven independent variables (henceforth, this model will be called model 1). In the second model, the variable $D_{\mathrm{DBH}}$ was not included (henceforth, called model 2). The models can be written as:

$$
\begin{aligned}
\ln \left(\frac{p_{k}}{p_{0}}\right)=Z_{k}= & \beta_{i 1} \mathrm{DBH}+\beta_{i 2} \mathrm{DBH}^{2}+\beta_{i 3} \mathrm{BAL} \\
& +\beta_{i 4} \mathrm{SI}+\beta_{i 5} A+\beta_{i 6} \mathrm{SDI}+\beta_{i 7} D_{D B H}
\end{aligned}
$$

$$
\begin{aligned}
\ln \left(\frac{p_{k}}{p_{0}}\right)=Z_{k}= & \beta_{i 1} \mathrm{DBH}+\beta_{i 2} \mathrm{DBH}^{2}+\beta_{i 3} \mathrm{BAL} \\
& +\beta_{i 4} \mathrm{SI}+\beta_{i 5} A+\beta_{i 6} \mathrm{SDI}
\end{aligned}
$$

Both equations above applied for $k=1,2, \ldots, K$, and $\beta_{i 1}, \ldots, \beta_{i 7}$ were parameters to be estimated. Note that in both cases, a zero intercept was assumed to normalize the model, as proposed by Greene (2000). The maximum likelihood method was used to estimate the parameters of the models. The analysis was performed with the SAS v.9.1 program using PROC LOGISTIC procedure (SAS Institute Inc. 2004). Once the parameters were estimated, we obtained the estimated values $\widehat{Z}_{k}$. Finally, the 
estimated probabilities $\widehat{p}_{k}$ for each individual tree were obtained. The specific expression of MNL regression was given by

$\widehat{p}_{k}=\frac{\widehat{e}^{\widehat{Z}_{k}}}{1+\sum_{l=1}^{K} \widehat{e}^{\widehat{Z}_{l}}}$ for $k=1,2, \ldots, K$ and

$\widehat{p}_{0}=\frac{1}{1+\sum_{l=1}^{K} e^{\widehat{Z}_{l}}}$

The dependent variable was multinomial with four and five possible components (Maritime pine and Scots pine, respectively). We denoted each component as upgrowth diameter classes ( $K$ was 1, 2, 3, 4, or 5). Now, let us suppose that we have a stand with fixed values SI, $A$, SDI and let $\mathrm{DBH}_{i}$ be the center of the diameter class $i$ in centimeters and $N_{i}$ is the number of trees per hectare in this class for each $i=1,2, \ldots I$. We can then calculate basal area in square meters by hectare for class $i$ as $\mathrm{BA}=N_{i} \pi / 4\left(\mathrm{DBH}_{i}\right)^{2}$ and $\mathrm{BAL}$ in square meters by for class $i$ as $\mathrm{BAL}_{i}=\sum_{l=i+1}^{I} \mathrm{BA}_{i}$ for $i=$ $1,2, \ldots, I-1$ (evidently $\mathrm{BAL}_{i}=0$ ). Using $\mathrm{MNL}$ regression, these values allow estimating probabilities $\widehat{p}_{k}\left(\mathrm{DBH}_{i}, \mathrm{BAL}_{i}\right.$, $S I, A, \mathrm{SDI}, 0.5)$ or $\widehat{p}_{k}\left(\mathrm{DBH}_{i}, \mathrm{BAL}_{i}, \mathrm{SI}, A, \mathrm{SDI}\right)$, depending on the model used. Finally, if $\pi_{i j}$ denotes the transition probability between diameter classes $i$ and $j$ at the end of the growth period, in model 1 , we can estimate probability in the following way:

$\widehat{\pi}_{i j}=\widehat{p}_{j-i}\left(\mathrm{DBH}_{i}, \mathrm{BAL}_{i}, \mathrm{SI}, A, \mathrm{SDI}, 0.5\right)$ for

$j=i, i+1, \ldots, i+K$

or, if appropriate, to implement model 2, as follows:

$$
\begin{aligned}
\widehat{\pi}_{i j} & =\widehat{p}_{j-i}\left(\mathrm{DBH}_{i}, \mathrm{BAL}_{i}, \mathrm{SI}, A, \mathrm{SDI}\right) \text { for } \\
j & =i, i+1, \ldots, i+K .
\end{aligned}
$$

These values defined matrix transitions of probabilities. Thus, stand evolution could now be projected over several periods. No growth was used as a categorical reference. Therefore, the MNL estimates of transition probabilities were expressed in $k$ events (depending on the species). The data were randomly divided into two subsets for model fitting and testing model $(80 \%$ and $20 \%$ of the total number of dataset, respectively). Once the model was selected, the entire dataset, for both species, was used for estimating parameters and transition probabilities of a matrix growth model.

\section{Results}

\subsection{Diameter growth model}

Model response was multi-categorical. Our modeling approach using MNL regression was able to estimate four upgrowth diameter classes for Maritime pine stands and five events for Scots pine stands. Our results revealed that size $(\mathrm{DBH})$ for Scots pine and age $(A)$ for Maritime pine have influence on growth. For both species, site productivity (SI) showed a remarkable effect on diameter growth model (Table 3).

\subsection{Parameters, selection, and validation of the MNL} models

Results of the adjusted $R^{2}$ test fitted were acceptable $\left(R^{2}=0.54\right.$ in Scots pine stands and $R^{2}=0.57$ in Maritime pine stands). Model 1 fits the data better than model 2, as the low AIC values show (Table 2). However, model 2 could also be considered useful. Although model 2 shows lower adjusted $R^{2}$ values than model 1 , the former uses only stand and diameter class information. The coefficient estimates of the model selected (Eqs. 1 and 2) were 35 and 28 for Scots pine and Maritime pine, respectively. The number of estimate parameters on models differed due to $k$ diameter class predicted and the number of independent variables used. In model 2, $\mathrm{DBH}^{2}$ was not significant in Maritime pine stands, so the number of parameters was consequently reduced to only 20 and 30, respectively.

The MNL regression results for both models are shown in Table 3. The estimated parameters of the selected growth models were consistent and had reasonable values and signs. For both species, diameter class growth was higher

\begin{tabular}{|c|c|c|c|c|c|c|c|}
\hline Species & Model & No. of parameters & AIC & $\mathrm{SC}$ & $-2 \log L$ & Generalized $R^{2 \mathrm{a}}$ & Adjusted $R^{2 \mathrm{~b}}$ \\
\hline P. sylvestris & 1 & 35 & $6,766.82$ & $6,987.73$ & $6,696.82$ & 0.8805 & 0.5361 \\
\hline P. pinaster & 1 & 28 & $4,915.75$ & $5,088.58$ & $4,859.75$ & 0.8774 & 0.5687 \\
\hline P. sylvestris & 2 & 30 & $7,842.30$ & $8,031.65$ & $7,782.30$ & 0.8353 & 0.4624 \\
\hline$P$. pinaster & 2 & 20 & $6,151.01$ & $6,274.46$ & $6,111.01$ & 0.8077 & 0.4624 \\
\hline
\end{tabular}

Table 2 Statistical parameters of the models (models 1 and 2)

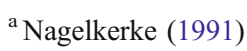

${ }^{\mathrm{b}}$ McFadden (1979) 
Table 3 Maximum likelihood estimates of transition model parameters (models 1 and 2)

\begin{tabular}{|c|c|c|c|c|c|}
\hline \multirow[t]{2}{*}{ Variable } & \multirow{2}{*}{$\begin{array}{l}\text { Upgrowth } \\
\text { (k) }\end{array}$} & \multicolumn{2}{|l|}{ Pinus sylvestris L. } & \multicolumn{2}{|l|}{ Pinus pinaster Ait. } \\
\hline & & Model 1 & Model 2 & Model 1 & Model 2 \\
\hline \multirow[t]{5}{*}{ DBH } & 1 & $0.20095(0.01940)$ & $0.07080(0.01680)$ & $0.13051(0.03110)$ & $-0.04150(0.00961)$ \\
\hline & 2 & $0.23324(0.02510)$ & $0.06480(0.02160)$ & $0.01840(0.04280) \mathrm{ns}$ & $-0.13940(0.01430)$ \\
\hline & 3 & $0.19599(0.04760)$ & $0.00647(0.04420) \mathrm{ns}$ & $-0.16177(0.08090)$ & $-0.22200(0.03000)$ \\
\hline & 4 & $0.68821(0.13340)$ & $0.45350(0.12830)$ & $-0.01083(0.32760)$ & $-0.49180(0.09910)$ \\
\hline & 5 & $2.26191(1.28790) \mathrm{ns}$ & $1.79190(1.03830) \mathrm{ns}$ & & \\
\hline \multirow[t]{5}{*}{$\mathrm{DBH} \times \mathrm{DBH}$} & 1 & $-0.00252(0.00028)$ & $-0.00078(0.00024)$ & $-0.00327(0.00053)$ & \\
\hline & 2 & $-0.00290(0.00036)$ & $-0.00067(0.00031)$ & $-0.00325(0.00073)$ & \\
\hline & 3 & $-0.00204(0.00068)$ & $0.00049(0.00063) \mathrm{ns}$ & $-0.00185(0.00147) \mathrm{ns}$ & \\
\hline & 4 & $-0.01084(0.00255)$ & $-0.00767(0.00250)$ & $-0.01320(0.00924) \mathrm{ns}$ & \\
\hline & 5 & $-0.03698(0.02490) \mathrm{ns}$ & $-0.02910(0.01970) \mathrm{ns}$ & & \\
\hline \multirow[t]{5}{*}{$D_{\mathrm{DBH}}$} & 1 & $-4.62635(0.20120)$ & & $-6.74732(0.29640)$ & \\
\hline & 2 & $-6.70679(0.26200)$ & & $-9.58148(0.36650)$ & \\
\hline & 3 & $-8.05233(0.52300)$ & & $-12.03700(0.65910)$ & \\
\hline & 4 & $-8.46499(1.00170)$ & & $-12.03259(1.26950)$ & \\
\hline & 5 & $-6.85632(2.08210)$ & & & \\
\hline \multirow[t]{5}{*}{ BAL } & 1 & $-0.02067(0.00398)$ & $-0.01600(0.00348)$ & $-0.05204(0.00627)$ & $-0.03480(0.00496)$ \\
\hline & 2 & $-0.04190(0.00533)$ & $-0.03580(0.00474)$ & $-0.11505(0.00900)$ & $-0.08670(0.00760)$ \\
\hline & 3 & $-0.03029(0.01200)$ & $-0.02220(0.01170) \mathrm{ns}$ & $-0.19077(0.01900)$ & $-0.14200(0.01730)$ \\
\hline & 4 & $-0.04151(0.03560) \mathrm{ns}$ & $-0.03560(0.03640) \mathrm{ns}$ & $-0.20892(0.03980)$ & $-0.17490(0.03720)$ \\
\hline & 5 & $0.22798(0.23370)$ & $0.21820(0.21200) \mathrm{ns}$ & & \\
\hline \multirow[t]{5}{*}{ SI } & 1 & $0.08966(0.01310)$ & $0.04610(0.01170)$ & $0.33824(0.02400)$ & $0.18150(0.01660)$ \\
\hline & 2 & $0.18790(0.01600)$ & $0.12720(0.01390)$ & $0.64304(0.03230)$ & $0.40740(0.02270)$ \\
\hline & 3 & $0.25343(0.02610)$ & $0.18360(0.02410)$ & $0.83418(0.05920)$ & $0.49200(0.04320)$ \\
\hline & 4 & $0.13514(0.05610)$ & $0.07270(0.05500) \mathrm{ns}$ & $0.67512(0.12930)$ & $0.46440(0.08370)$ \\
\hline & 5 & $-0.47720(0.45880) \mathrm{ns}$ & $-0.44010(0.37150) \mathrm{ns}$ & & \\
\hline \multirow[t]{5}{*}{$A$} & 1 & $-0.01206(0.00210)$ & $-0.00908(0.00183)$ & $0.01407(0.00376)$ & $0.00999(0.00268)$ \\
\hline & 2 & $-0.02550(0.00310)$ & $-0.02120(0.00279)$ & $0.02354(0.00546)$ & $0.01370(0.00416)$ \\
\hline & 3 & $-0.04097(0.00814)$ & $-0.03630(0.00791)$ & $0.04339(0.01120)$ & $0.02060(0.00983)$ \\
\hline & 4 & $-0.08309(0.02850)$ & $-0.07580(0.02830)$ & $0.04067(0.03050) \mathrm{ns}$ & $0.03950(0.02380) \mathrm{ns}$ \\
\hline & 5 & $-0.23899(0.19650) \mathrm{ns}$ & $-0.22950(0.19070) \mathrm{ns}$ & & \\
\hline \multirow[t]{5}{*}{ SDI } & 1 & $0.00001(0.00023) \mathrm{ns}$ & $-0.00005(0.00020) \mathrm{ns}$ & $0.00015(0.00032) \mathrm{ns}$ & $-0.00012(0.00025) \mathrm{ns}$ \\
\hline & 2 & $-0.00170(0.00029)$ & $-0.00166(0.00025)$ & $-0.00176(0.00044)$ & $-0.00218(0.00035)$ \\
\hline & 3 & $-0.00433(0.00056)$ & $-0.00424(0.00053)$ & $-0.00330(0.00083)$ & $-0.00373(0.00074)$ \\
\hline & 4 & $-0.00692(0.00150)$ & $-0.00649(0.00140)$ & $0.00001(0.00214) \mathrm{ns}$ & $0.00039(0.00200) \mathrm{ns}$ \\
\hline & 5 & $-0.01992(0.01070) \mathrm{ns}$ & $-0.01730(0.00916) \mathrm{ns}$ & & \\
\hline
\end{tabular}

Asymptotic standard errors are given in parentheses

$n s$ not significant (all other variables are significant at $p<0.05$ )

on the better sites. It was observed that when DBH increased, the coefficient parameters of $\beta_{i 1}$ decreased, whereas as stand age increased, parameters of $\beta_{i 5}$ increased (see Table 3 for Maritime pine, model 1). Opposite effects were observed for Scots pine when the same variables were analyzed. The $D_{\mathrm{DBH}}$ variable had a negative effect on diameter growth prediction ( $k$ diameter class) for both species.
We validated models with a portion of the total dataset selected randomly $(20 \%)$. The validation method indicated that the model could be applied across a wide range of growth conditions and forest structure. We compared and analyzed the observed and predicted diameter growth data. Table 4 shows that the models successfully predicted diameter growth. Figure $1 \mathrm{a}, \mathrm{b}$ illustrates the performances of models 1 and 2 against 
Table 4 DBH upgrowth validation for $P$. sylvestris $\mathrm{L}$. and $P$. pinaster Ait

\begin{tabular}{|c|c|c|c|c|c|c|c|c|}
\hline \multirow[t]{2}{*}{ Species } & \multirow[t]{2}{*}{ Observed $(K)$} & \multicolumn{6}{|c|}{ Predicted upgrowth (\%) } & \multirow[t]{2}{*}{ Trees $(n)$} \\
\hline & & 0 & 1 & 2 & 3 & 4 & 5 & \\
\hline \multirow[t]{6}{*}{ P. sylvestris (model 1) } & 0 & 46.72 & 51.92 & 1.36 & 0.00 & 0.00 & 0.00 & 884 \\
\hline & 1 & 9.68 & 85.91 & 4.41 & 0.00 & 0.00 & 0.00 & 2356 \\
\hline & 2 & 2.79 & 74.93 & 22.28 & 0.00 & 0.00 & 0.00 & 718 \\
\hline & 3 & 0.00 & 41.76 & 57.14 & 0.00 & 1.10 & 0.00 & 91 \\
\hline & 4 & 0.00 & 26.32 & 57.89 & 0.00 & 15.79 & 0.00 & 19 \\
\hline & 5 & 0.00 & 0.00 & 0.00 & 66.67 & 33.33 & 0.00 & 3 \\
\hline \multirow[t]{5}{*}{ P. pinaster (model 1) } & 0 & 54.57 & 45.27 & 0.16 & 0.00 & 0.00 & - & 645 \\
\hline & 1 & 8.06 & 85.65 & 6.29 & 0.00 & 0.00 & - & 2195 \\
\hline & 2 & 1.15 & 56.14 & 42.55 & 0.16 & 0.00 & - & 611 \\
\hline & 3 & 0.00 & 29.33 & 70.67 & 0.00 & 0.00 & - & 75 \\
\hline & 4 & 0.00 & 12.50 & 87.50 & 0.00 & 0.00 & - & 16 \\
\hline \multirow[t]{6}{*}{ P. sylvestris (model 2) } & 0 & 2.94 & 95.48 & 1.58 & 0.00 & 0.00 & 0.00 & 884 \\
\hline & 1 & 1.36 & 94.57 & 4.07 & 0.00 & 0.00 & 0.00 & 2356 \\
\hline & 2 & 0.28 & 81.89 & 17.83 & 0.00 & 0.00 & 0.00 & 718 \\
\hline & 3 & 0.00 & 56.04 & 43.96 & 0.00 & 0.00 & 0.00 & 91 \\
\hline & 4 & 0.00 & 31.58 & 68.42 & 0.00 & 0.00 & 0.00 & 19 \\
\hline & 5 & 0.00 & 33.33 & 66.67 & 0.00 & 0.00 & 0.00 & 3 \\
\hline \multirow[t]{5}{*}{ P. pinaster (model 2) } & 0 & 1.24 & 97.98 & 0.78 & 0.00 & 0.00 & - & 645 \\
\hline & 1 & 0.23 & 93.58 & 6.20 & 0.00 & 0.00 & - & 2195 \\
\hline & 2 & 0.00 & 64.81 & 35.19 & 0.00 & 0.00 & - & 611 \\
\hline & 3 & 0.00 & 44.00 & 56.00 & 0.00 & 0.00 & - & 75 \\
\hline & 4 & 0.00 & 37.50 & 62.50 & 0.00 & 0.00 & - & 16 \\
\hline
\end{tabular}

some independent variables (A, SDI, BA, and SI). The success rate in predicting no growth class change was $54.6 \%$ for Maritime pine stands and $46.7 \%$ for Scots pine stands. Although the overall average of diameter growth predictions was acceptable $(k=1$ predicted substantially more than $85 \%$ ), it appears that the MNL models produce larger negative biases (sub-estimation) for larger growth diameter classes (e. g., $k=2$ and 3). However, model 1 shows a better prediction for Maritime pine stands than for Scots pine stands, except within a particular range of site productivity (from 13 to $23 \mathrm{~m}$ ). It was clear that model 1 produced more consistent and accurate results than model 2 . In short, the behavior of the models was satisfactory, showing a high percentage of prediction accuracy.

The highest prediction rate of the model for both species occurred for the growth of one diameter class (more than $85 \%$ successful predictions). The model showed balanced predictions, mainly for Maritime pine stands (no change in diameter class, growth by one or two diameter classes). The loss of prediction accuracy of the model occurred in larger upgrowth diameter classes $(k \geq 3)$ due to the low stem number in these diameter classes. Figure 1a, b shows the success ratio of the model selected as it relates to some independent variables. As far as we can see, the success ratio of the diameter growth model with respect to some independent variables was quite similar for models 1 and 2. The performance of the model selected in successful rate prediction was higher for Maritime pine than for Scots pine, although some exceptions have been observed (Fig. 1a).

\subsection{Transition probabilities of diameter growth}

Multinomial equations allow the estimation of transition probabilities. Probabilities of tree diameter growth may be better explained in Scots pine stands than in Maritime pine stands. The width of diameter classes should be small enough to estimate transition probability in Mediterranean pine forests. In our study, we used diameter growth classes at 1-cm width. This allowed us to observe five (Scots pine) and four (Maritime pine) maximum diameter growth classes. Boltz and Carter (2006) used multinomial formulation for estimating probabilities from one to three events (mortality, stability, and upgrowth). Successful model predictions were very high for no growth $(k=0)$ and one-step diameter growth $(k=1)$. Differences were observed only in the larger upgrowth diameter class prediction $(k \geq 3)$ due to the smaller number of individual trees in these classes. The growth transitions in simulated forest conditions were slightly different among species studied. 
Fig. 1 Model validations are presented taking into account successful ratio of diameter growth prediction in relation to some independent variables. The success ratio was obtained between successful predictions by the models ( $k$ upgrowth diameter class) and diameter growth observed in the period studied a) Model 1

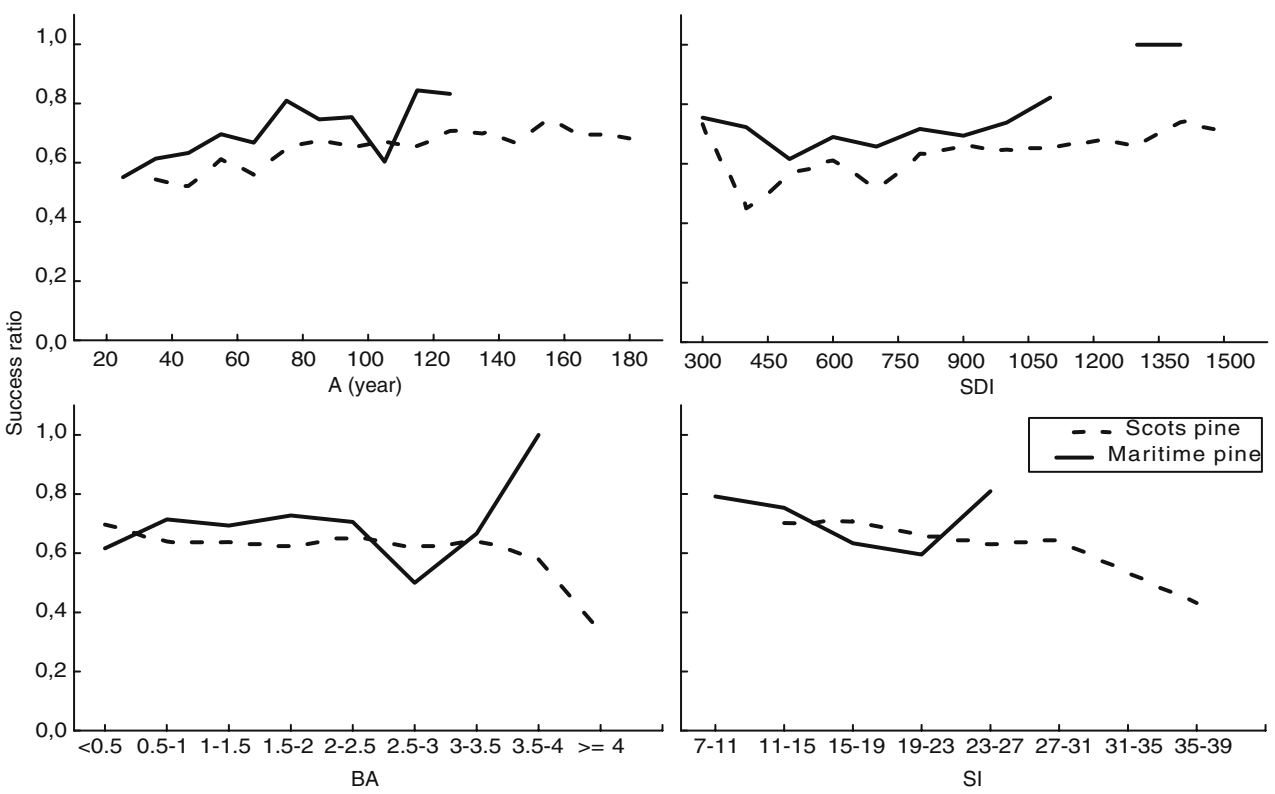

b) Model 2

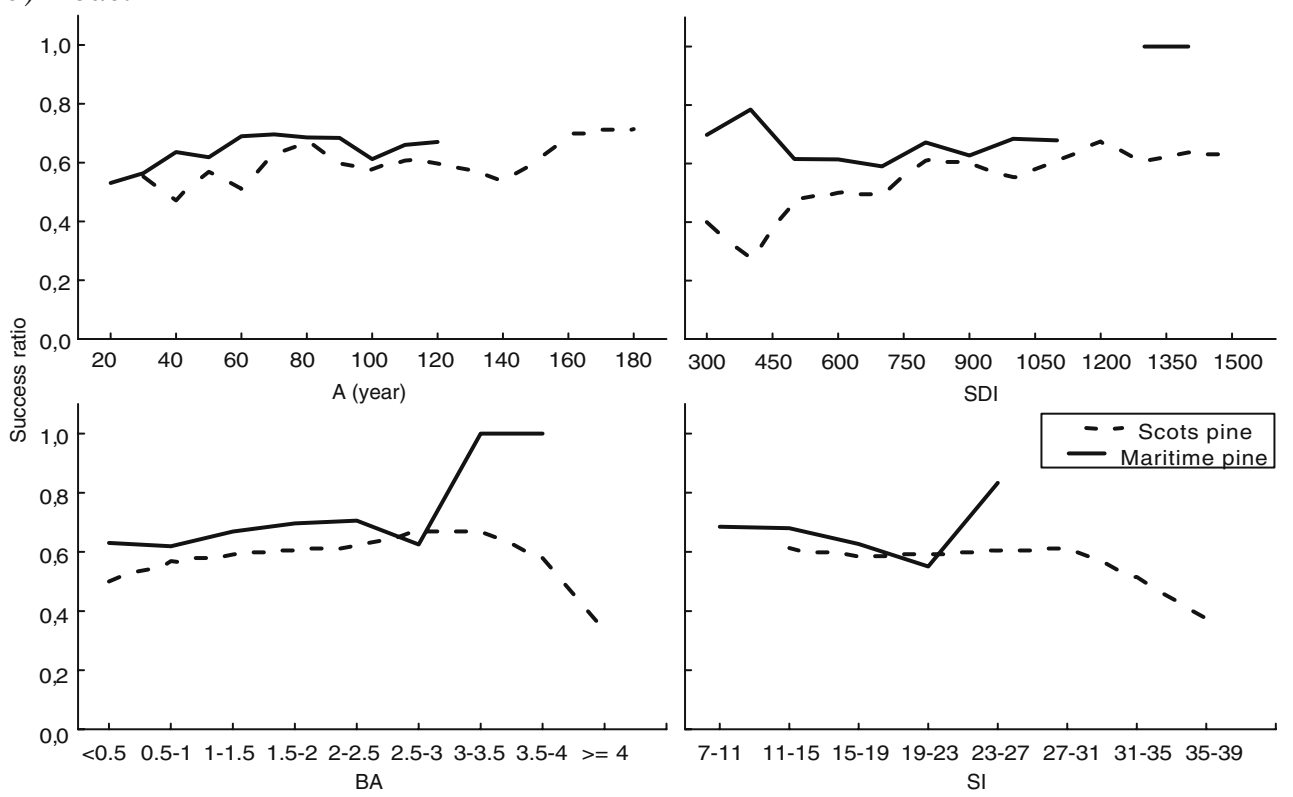

\section{Discussion}

4.1 MNL growth model for Mediterranean pine forests

A matrix model to predict diameter upgrowth transition based on MNL regression for two Mediterranean pines in Spain has been developed. The independent variables included in the models represent the main factors affecting tree growth (size, productivity, competition, density, and age). The MNL model predicts greater $k$ diameter growth when stand age ranged from 60 to 100 and SDI was lower for Scots pine stands (Fig. 1a). In the present study, stand ingrowth and mortality were not considered in the matrix model. Buongiorno and Michie (1980) modeled the recruitment of Sugar maple (Acer saccharum Marsh.) to predict long-term growth of undisturbed and managed stands in central and northern Wisconsin and the upper Michigan peninsula (USA). Buongiorno et al. (1995) developed a deterministic model to predict stand evolution.

MNL has been used because this methodology allows a multi-response analysis. In some cases, the results are difficult to interpret given the large number of parameters estimated by the model. To avoid overparameterization of the models, Shimatani (2007) demonstrated effects of increasing intervals using 1- and 2-cm intervals on Camellica japonica and Dendropanax trifidus; the conclusion was that 
Fig. 2 Simulated upgrowth probabilities versus tree DBH for various stand conditions (DBH classes are $1 \mathrm{~cm}$ in width) (a) Simulation per upgrowth diameter class, various stand densities (SDI) and site index (SI) for Scots pine stands: Stand conditions: $D_{\mathrm{DBH}}=0.5$, BAL $=0$, $\mathrm{A}=50, \mathrm{SI}=17$ and $23, \mathrm{SDI}=400$, 700, 1000, 1300 (b) Simulation per upgrowth diameter class, various stand densities (SDI) and site index (SI) for Maritime pine stands: Stand conditions: $D_{\mathrm{DBH}}=0.5, \mathrm{BAL}=0, \mathrm{~A}=50, \mathrm{SI}=9$ and $14, \mathrm{SDI}=400,700,1000$, 1300
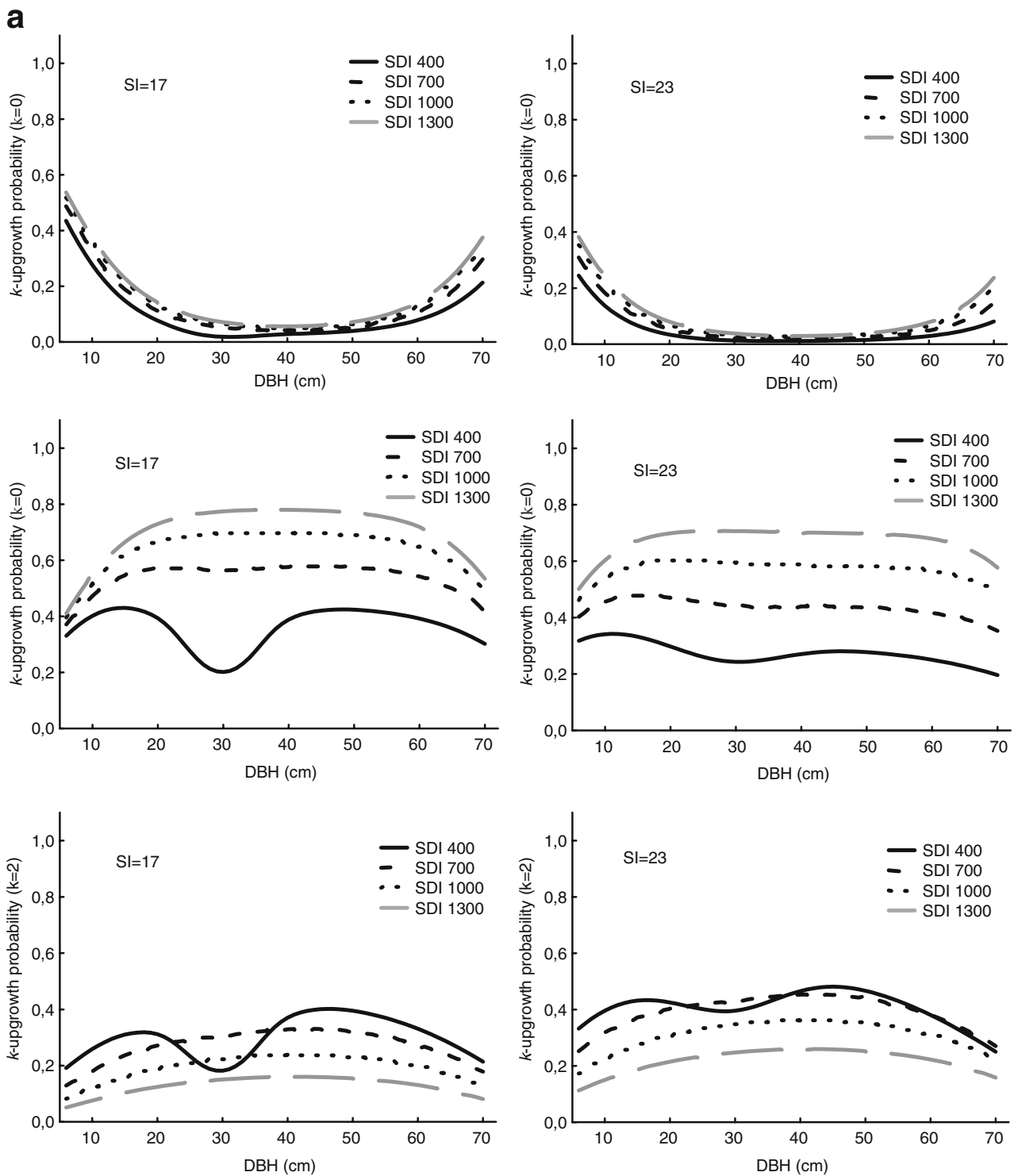

smaller interval classes were better, but as we will need more parameters, an equilibrium point between the number of classes and parameters must be found. In our study, we have achieved a balance between the number of diameter classes and parameters estimated by the models. The growth classes predicted from MNL show an alternative technique for forest growth modeling in Mediterranean forestry. Data in studies on the tropics such as differences among ecological guilds (Boltz and Carter 2006), product distribution from regional inventories (Teeter and Zhou 1998), and lumber grades and byproducts yields in Scots pine (Lyhykäinen et al. 2009) have been predicted by MNL regression. In Finland, strategic groups were identified by MNL using forest owner and forest holding characteristics as explanatory variables (Kurttila et al. 2001). Studying Pinus tadea L. and Pinus echinata Mill. stands, Prestemon and Buongiorno (2000) used discrete multinomial logit and tobit models to predict the probability that a stem or log belonged to a certain quality class.

Another question is the choice of the diameter class to be used. Division into size classes inevitably involves some subjectivity. A diameter class width similar to ours was used by Shimatani et al. (2007) for forests on Tsushina Island. In other forest types, López et al. (2008) estimated population growth rates with respect to the width of the diameter classes using matrix models for beech (F. sylvatica L.) stands in Navarra (Spain). Wider diameter classes are usually chosen in tropical forests: for example, six diameter classes were used in the construction of matrix models for tree population projection in a tropical rainforest of southwestern Nigeria (Osho 1991). The diameter distribution can be a reference to choose the width of the diameter class (López Torres et al. 2008), although narrow size classes are 
Fig. 2 (continued)
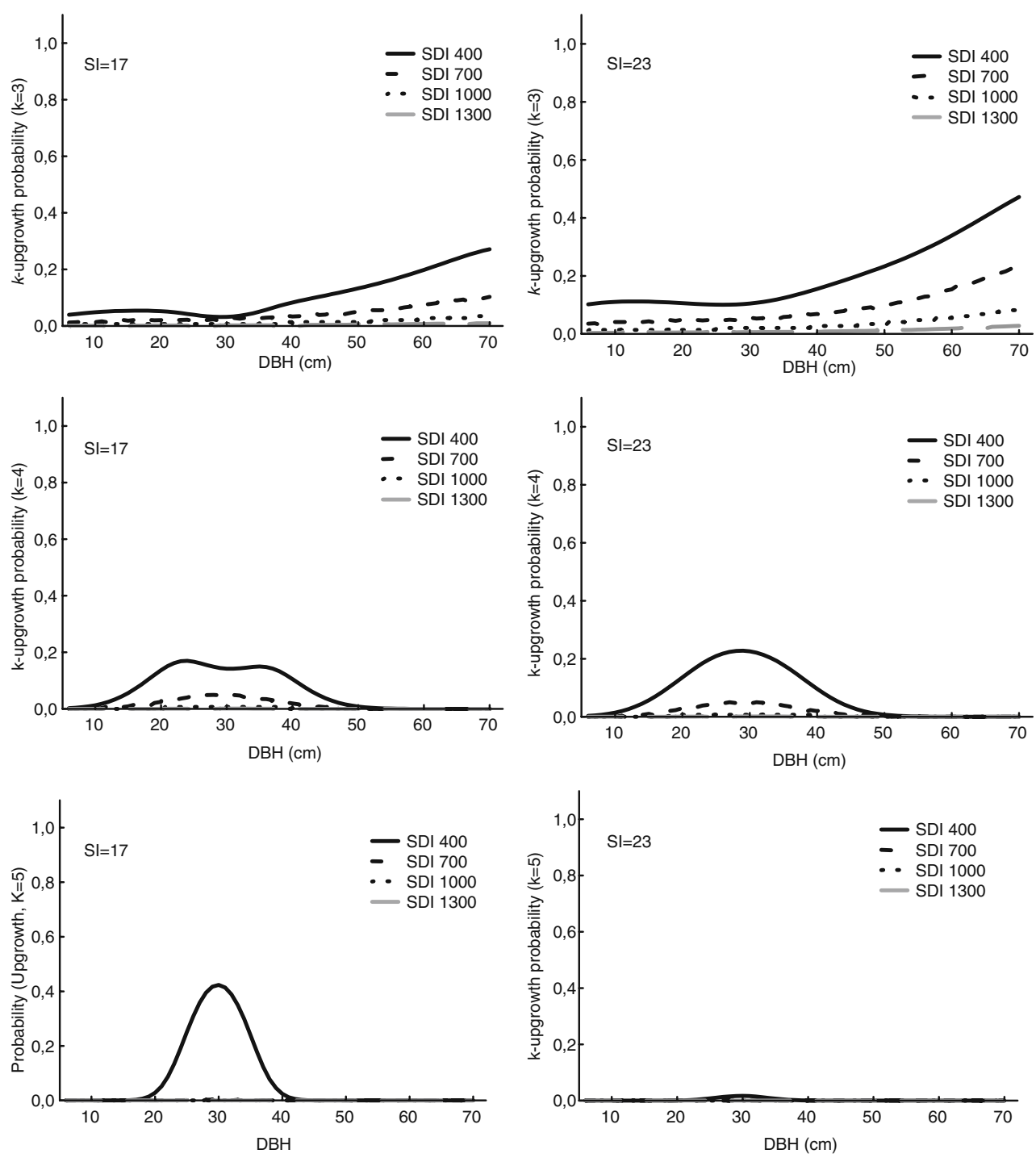

recommended in demographic studies using integral projection models (Zuidema et al. 2010). In other studies, various widths of the diameter class have been used (Lin et al. 1998; Boltz and Carter 2006), including trees in $5.1 \mathrm{~cm}$ for Loblolly pine stands, $5 \mathrm{~cm}$ in dry forests, or $4 \mathrm{~cm}$ for uneven-aged mixed-species forests (Hao et al. 2005).

On the other hand, diameter growth matrix model performance is affected by diameter class width (Picard et al. 2003). In this study, we used 1-cm diameter class width because it allows better grouping of all individual trees. This width is smaller than the width used in other previous matrix models (Buongiorno et al. 1994), but is similar to the width used in other models (Picard et al. 2003). As we can see, different widths of size classes were used in previous studies, while our proposal used very fine classes and calculated a transition probability for every pair of classes. In population dynamics of tree species in Japanese forests, matrix models constructed based on Bayesian non-parametric estimation used also fine diameter classes (Shimatani et al. 2007). In summary, many authors argue that narrow categories (1.3- to 3-cm DBH) should be used in tree matrix models to obtain the best estimations of tree age, population growth rate, and elasticity.

By comparing model behavior against different variables (Fig. 2a, b), we can evaluate the model performance and gain insight into forest dynamics, as well as obtain information useful for developing adequate management paths. Vanclay (1995) assumed, for transition matrices, that a tree in one of a finite number of size classes has a known probability of moving to another class, dependent only upon its current size. However, in our study, the upgrowth probability depended not only on tree size but also on stand characteristics such as density, competition, age, and productivity. The transition probabilities that the model assigned for each individual tree were evaluated considering only the maximum probability predicted for that tree. 
Fig. 2 (continued)
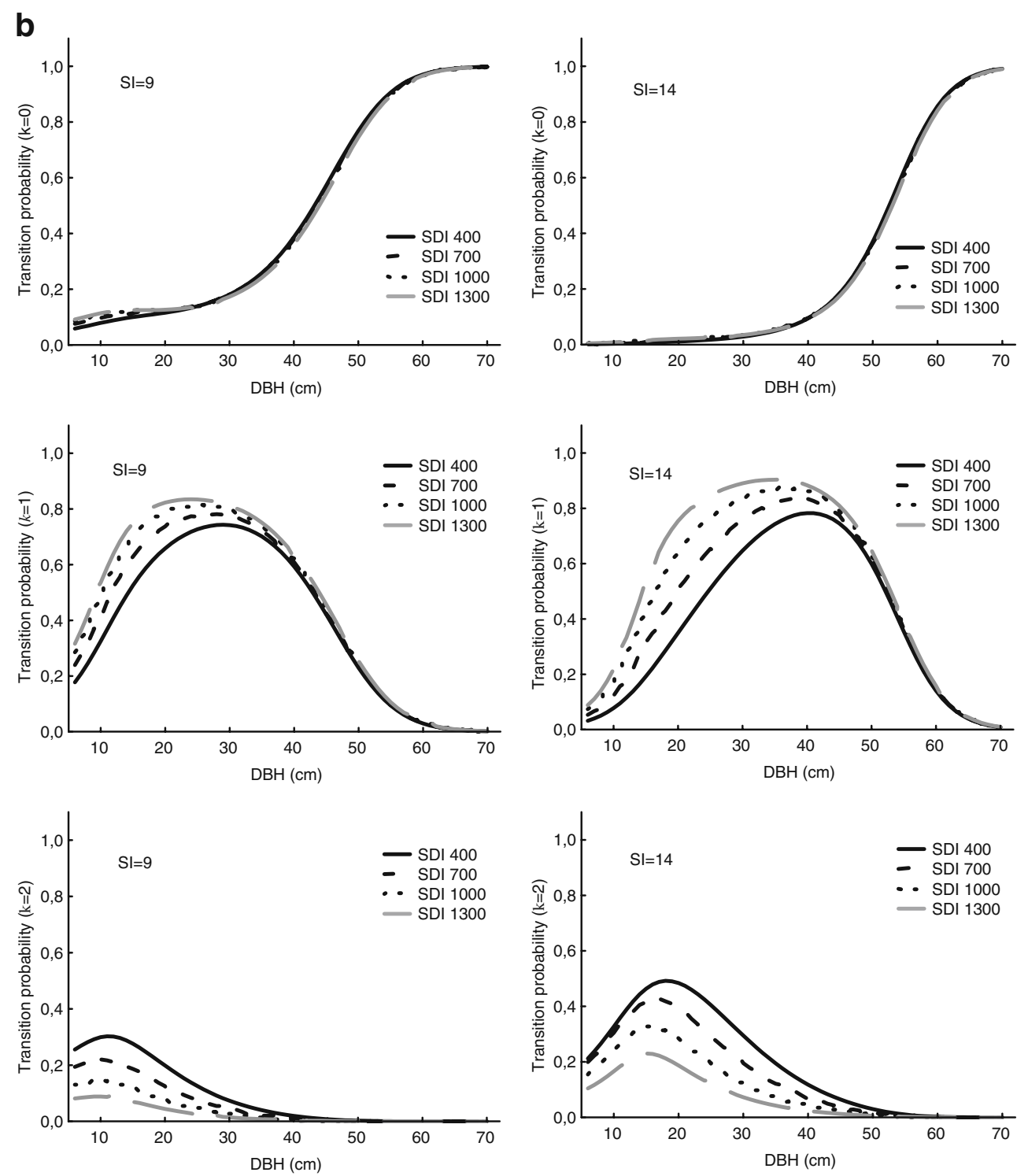

Picard et al. (2003) found a high sensitivity of diameter width when they modeled diameter class distribution using a second-order matrix model.

Age influenced diameter growth rates in both species. The upgrowth probability increased for Maritime pine stands and decreased for Scots pine stands. The effect of stand density on diameter growth (Buongiorno et al. 1995) was negative in the species studied, as had been previously reported in Loblolly pine stands (Lin et al. 1998). The model performance is adequate (success rate over $50 \%$ ) along different variables (A, BA, SDI, DBH, and SI). However, performance decreases for extreme values (low or high), in some cases to below $40 \%$. More data would be needed to improve these predictions for extreme values. The MNL model was used to study differences in stand development using transitions influenced by changing stand characteristics (Boltz and Carter 2006). Site index is a proxy of forest productivity that reflects environmental factors at the stand level. In growth simulations presented here for Scots pine and Maritime pine stands, large growth variations were shown for each $k$ probability in relation to site quality and density.

\subsection{Growth simulations of Mediterranean pine forests}

Simulations were widely used to evaluate differences in stand development (Buongiorno and Michie 1980; Miina 1993). To illustrate our growth models and their applicability, we performed simulations for both species in two different forest conditions. We varied initial stand densities (SDI $=400,700,1,000$, and 1,300) and site index: (a) Scots pine stands (SI=17 and $23 \mathrm{~m}$ ) and (b) Maritime pine stands $(\mathrm{SI}=9$ and $14 \mathrm{~m})$. Stand age $(A=50$-year), basal area in larger trees $(\mathrm{BAL}=0)$, and $D_{\mathrm{DBH}}(0.5 \mathrm{~cm})$ were fixed. Such 
Fig. 2 (continued)
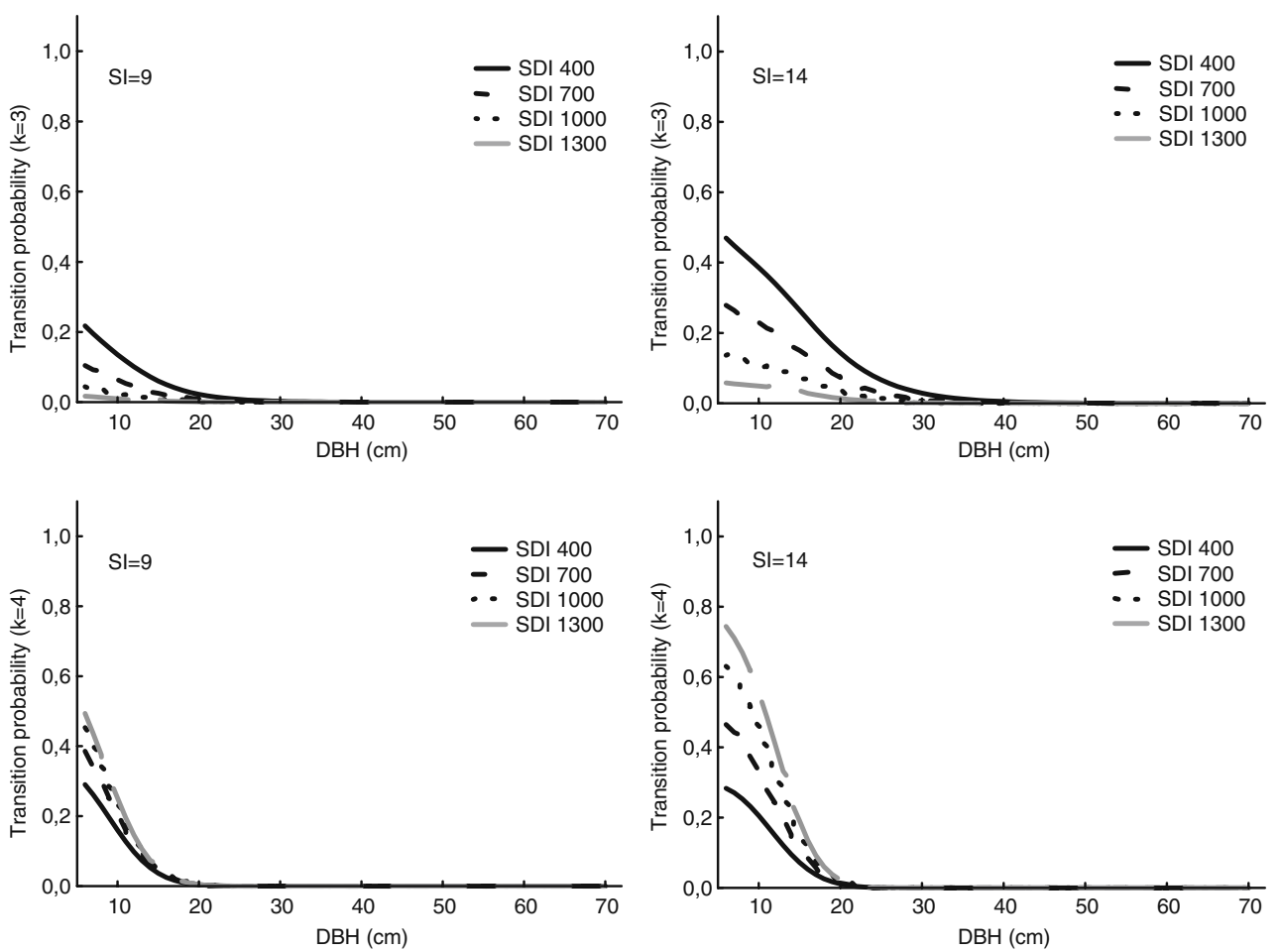

simulation results are illustrated in detail in Fig. 2. The impact of site index was lower in Maritime pine stands than in Scots pine stands, although the probability patterns were highly different. Our simulations supported by similar findings in other studies (Bravo and Montero 2001; Bravo-Oviedo et al. 2004) indicate that forest growth increases at the better sites. Transition probabilities in the stand simulations were higher in the better sites even though different stand densities occurred. For Scots pine in dense stands, upgrowth probability increased for $k=1$ and decreased in the rest ( $k=2$ and 3). For Maritime pine stands, curve shape of the transition probabilities was slightly similar among densities for each $k$ upgrowth simulated. No upgrowth $(k=0)$ showed large differences in upgrowth prediction for both species.

A similar constant parameter transition probability across diameter classes was observed by Hao (2005). As we expected, site quality is positively related to diameter growth, indicating that trees are attaining larger diameter growth in the better sites. Evidently, climate and soil differences may also cause variations in growth, some of which are not reflected by the site index variable used here. In general, low growth rates were observed in larger diameter trees, probably related to the tree maturity. In addition, Scots pine trees showed a lower upgrowth rate because they are more sensitive to inter-tree competition. Low density of stands shows a higher upgrowth rate probability, so trees in these stands are more likely to grow by two or more classes.
A growth model for Scots pine and Maritime pine in Spain was fitted. Although further research is needed to assess more accurately growth dynamics in the studied stands (e.g., by introducing environmental change conditions), our results can help operational forestry to evaluate alternative management regimes. The determination of forest growth is of tremendous importance to the forest resource manager. It can be deduced from the results obtained that model 1 should be used when DBH and $D_{\mathrm{DBH}}$ have been measured and calculated, respectively. When these variables previously described are not available, forest managers could run model 2 to predict diameter growth in pine stands. Both models are acceptable because of their simplicity of interpretation and use. As in other empirical models, matrix model performance is strongly dependent on its structure, which should reflect tree growth theory adequately. However, it could benefit from the inclusion of variables based on biological findings. The model developed in the present study can be considered a useful tool for simulating tree growth. The main limitation of our models derives from the fact that we have only used individual diameters and some variables related to stand structure to predict the upgrowth transition rates by diameter classes. By including environmental variables that can represent climate change effects (temperature, rainfall, etc.), we could obtain a more robust model. Likewise, equations that represent mortality, harvest, and ingrowth should be developed to improve the model. This approach has been used before to develop successful hybrid models and could improve matrix models in the near future. 
Acknowledgments This study is part of a research project (Code AGL-2007-65795-C02-01) funded by the Spanish Ministry of Science and Innovation. We are grateful for comments from the Editor and two journal reviewers. Senior author (E. Escalante) thanks the Spanish Agency for International Development Cooperation of the Ministry of Foreign Affairs and Cooperation of Spain for its support.

\section{References}

Boltz F, Carter DR (2006) Multinomial logit estimation of a matrix growth model for tropical dry forests of eastern Bolivia. Can J For Res 36:2623-2632

Bravo F, Montero G (2001) Site index estimation in Scots pine (Pinus sylvestris L.) stands in the High Ebro Basin (northern Spain) using soil attributes. Forestry 74:395-406

Bravo-Oviedo A, Del Río M, Montero G (2004) Site index curves and growth model for Mediterranean maritime pine (Pinus pinaster Ait.) in Spain. For Ecol Manage 201:187-197

Buongiorno J, Michie BR (1980) A matrix model of uneven-aged forest management. For Sci 26:609-625

Buongiorno J, Dahir S, Lu H-C et al (1994) Tree size diversity and economic returns in uneven-aged forest stands. For Sci 40:83-103

Buongiorno J, Peyron J-L, Houllier F et al (1995) Growth and management of mixed-species, uneven-aged forests in the French Jura: implications for economic returns and tree diversity. For Sci 41:397-429

Englin JE, McDonald JM, Moeltner K (2006) Valuing ancient forest ecosystems: an analysis of backcountry hiking in Jasper National Park. Ecol Econ 57:665-678

Greene WH (2000) Econometric analysis. Prentice Hall, Upper Saddle River, $860 \mathrm{pp}$

Hann DW, Hanus LM (2001) Enhanced mortality equations for trees in the mixed conifer zone of Southwest Oregon. For Res Lab Res Contrib 34:34

Hao QY, Meng FR, Zhu Y et al (2005) A transition matrix growth model for uneven-aged mixed-species forests in the Changbai Mountains, northeastern China. New For 29:221-231

Kurttila M, Hämäläinen K, Kajanus M et al (2001) Non-industrial private forest owners' attitudes towards the operational environment of forestry - a multinominal logit model analysis. For Policy Econ 2:13-28

Lin C-R, Buongiorno J, Prestemon J et al (1998) Growth model for uneven-aged Loblolly pine stands - simulations and management implications. Research Paper FPL-RP-569, USDA Forest Service, Forest Products Laboratory, Madison, WI

Lizarralde I (2008) Dinámica de rodales y competencias en las masas de pino silvestre (Pinus sylvestris L.) y pino negral (Pinus pinaster Ait.) de los Sistemas Central e Ibéricos. M.S. thesis, Universidad de Valladolid, Palencia, $230 \mathrm{pp}$

López Torres I, Fullana Belda C, Ortuño Pérez SF et al (2008) Choosing Fagus sylvatica L. matrix model dimension by sensitivity analysis of the population growth rate with respect to the width of the diameter classes. Ecol Model 218:307-314

Lowell KE, Mitchell RJ (1987) Stand growth projection — simultaneous estimation of growth and mortality using a single probabilistic function. Can J For Res 17:1466-1470

Lyhykäinen HT, Mäkinen H et al (2009) Predicting lumber grade and byproduct yields for Scots pine trees. For Ecol Manage 258:146-158
McFadden D (1979) Quantitative methods for analysing travel behaviour of individual: some recent developments. In: Hensher DA, Stopher PR (eds) Behavioural travel modelling. Croom Helm, London, pp 279-318

Miina J (1993) Residual variation in diameter growth in a stand of Scots pine and Norway spruce. For Ecol Manage 58:111-128

Mogas J, Riera P et al (2006) A comparison of contingent valuation and choice modelling with second-order interactions. J For Econ 12:5-30

Monserud RA, Sterba H (1999) Modeling individual tree mortality for Austrian forest species. For Ecol Manage 113:109-123

Nagelkerke NJD (1991) A note on a general definition of the coefficient of determination. Biometrika 78:691-692

Osho JSA (1991) Matrix model for tree population projection in a tropical rain forest of south-western Nigeria. Ecol Model 59:247-255

Picard N, Bar-Hen A et al (2003) Modelling diameter class distribution with a second-order matrix model. For Ecol Manage 180:389-400

Prestemon JP, Buongiorno J (2000) Determinants of tree quality and lumber value in natural uneven-aged southern pine stands. Can J For Res 30:211-219

Prinzie A, Van den Poel D (2008) Random forests for multiclass classification: random multinomial logit. Expert Syst Appl 34:1721-1732

Río M, Bravo F et al (2004) Influence of individual tree and stand attributes in stem straightness in Pinus pinaster Ait. stands. Ann For Sci 61:141-148

Roberts MR, Hruska AJ (1986) Predicting diameter distributions-a test of the stationary Markov model. Can J For Res 16:130-135

SAS Institute Inc. (2004) SAS/STAT 9.1 user's guide. SAS Institute Inc., Cary, NC, pp 2281-2468.

Shimatani IK, Kubota Y et al (2007) Matrix models using fine size classes and their application to the population dynamics of tree species: Bayesian non-parametric estimation. Plant Species Biol 22:175-190

Spathelf P, Durlo MA (2001) Transition matrix for modeling the dynamics of a subtropical seminatural forest in southern Brazil. For Ecol Manage 151:139-149

Teeter L, Zhou X (1998) A multinomial logit approach to estimating regional inventories by product class. In: Abt KL (ed) Proceedings of the 1998 Southern Forest Economics Workshop, Part II. Research Triangle Park, NC Southern Research Station, Williamsburg, Virginia, pp 238-242

Usher MB (1966) A matrix approach to management of renewable resources with special reference to selection forests. J Appl Ecol 3:355-367

Usher MB (1969) A matrix model for forest management. Biometrics 25:309-315

Vanclay JK (1995) Growth models for tropical forests - a synthesis of models and methods. For Sci 41:7-42

Volin VC, Buongiorno J (1996) Effects of alternative management regimes on forest stand structure, species composition, and income: a model for the Italian dolomites. For Ecol Manage 87:107-125

Wang X, Bennett J et al (2007) Estimating non-market environmental benefits of the Conversion of Cropland to Forest and Grassland Program: a choice modeling approach. Ecol Econ 63:114 125

Zuidema PA, Jongejans E et al (2010) Integral projection models for trees: a new parameterization method and a validation of model output. J Ecol 98:345-355 